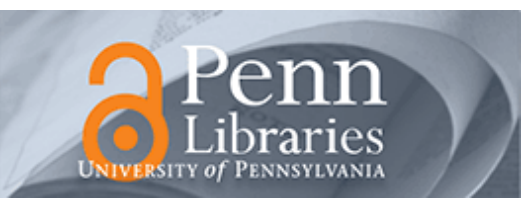

University of Pennsylvania

ScholarlyCommons

Health Care Management Papers

Wharton Faculty Research

$5-28-2015$

\title{
Randomized Trial of Four Financial-Incentive Programs for Smoking Cessation
}

\author{
Scott D. Halpern \\ University of Pennsylvania \\ Benjamin French \\ University of Pennsylvania - Biostatistics \\ Dylan S. Small \\ University of Pennsylvania \\ Kathryn Saulsgiver \\ University of Pennsylvania \\ Michael O. Harhay \\ University of Pennsylvania
}

See next page for additional authors

Follow this and additional works at: https://repository.upenn.edu/hcmg_papers

Part of the Medical Humanities Commons, and the Substance Abuse and Addiction Commons

\section{Recommended Citation}

Halpern, S. D., French, B., Small, D. S., Saulsgiver, K., Harhay, M. O., Audrain-McGovern, J., Loewenstein, G., Brennan, T. A., Asch, D. A., \& Volpp, K. G. (2015). Randomized Trial of Four Financial-Incentive Programs for Smoking Cessation. The New England Journal of Medicine, 372 (22), 2108-2117. http://dx.doi.org/ 10.1056/NEJMoa1414293

This paper is posted at ScholarlyCommons. https://repository.upenn.edu/hcmg_papers/25

For more information, please contact repository@pobox.upenn.edu. 


\title{
Randomized Trial of Four Financial-Incentive Programs for Smoking Cessation
}

\author{
Abstract \\ Background
}

Financial incentives promote many health behaviors, but effective ways to deliver health incentives remain uncertain.

Methods

We randomly assigned CVS Caremark employees and their relatives and friends to one of four incentive programs or to usual care for smoking cessation. Two of the incentive programs targeted individuals, and two targeted groups of six participants. One of the individual-oriented programs and one of the grouporiented programs entailed rewards of approximately $\$ 800$ for smoking cessation; the others entailed refundable deposits of $\$ 150$ plus $\$ 650$ in reward payments for successful participants. Usual care included informational resources and free smoking-cessation aids.

Results

Overall, 2538 participants were enrolled. Of those assigned to reward-based programs, $90.0 \%$ accepted this assignment, as compared with $13.7 \%$ of those assigned to deposit-based programs ( $P$

\section{Conclusions}

Reward-based programs were much more commonly accepted than deposit-based programs, leading to higher rates of sustained abstinence from smoking. Group-oriented incentive programs were no more effective than individual-oriented programs.

\section{Disciplines}

Medical Humanities | Substance Abuse and Addiction

\section{Author(s)}

Scott D. Halpern, Benjamin French, Dylan S. Small, Kathryn Saulsgiver, Michael O. Harhay, Janet AudrainMcGovern, George Loewenstein, Troyen A. Brennan, David A. Asch, and Kevin G. Volpp 


\title{
Randomized Trial of Four Financial- Incentive Programs for Smoking Cessation
}

\author{
Scott D. Halpern, M.D., Ph.D., Benjamin French, Ph.D., Dylan S. Small, Ph.D., \\ Kathryn Saulsgiver, Ph.D., Michael O. Harhay, M.P.H., \\ Janet Audrain-McGovern, Ph.D., George Loewenstein, Ph.D., \\ Troyen A. Brennan, M.D., J.D., David A. Asch, M.D., M.B.A., \\ and Kevin G. Volpp, M.D., Ph.D.
}

From the Departments of Medicine (S.D.H., D.A.A., K.G.V.), Biostatistics and Epidemiology (S.D.H., B.F., K.S., M.O.H.), Medical Ethics and Health Policy (S.D.H. K.G.V.), and Psychiatry (J.A.-M.) and the Center for Health Incentives and Behav ioral Economics at the Leonard Davis Institute of Health Economics (S.D.H., B.F., D.S.S., K.S., J.A.-M., G.L., D.A.A., K.G.V.), Perelman School of Medicine at the University of Pennsylvania, the Departments of Statistics (D.S.S.) and Health Care Management (D.A.A., K.G.V.), Wharton School, University of Pennsylvania Center for Health Equity Research and Promotion, the Philadelphia Veterans Affairs Medical Center (D.A.A., K.G.V.), and the Center for Health Care Innovation, University of Pennsylvania Health System (D.A.A., K.G.V.) - all in Philadelphia; the Center for Behavioral Decision Research, Carnegie Mellon University, Pittsburgh (G.L.); and CVS Caremark, Woonsocket, RI (T.A.B.). Address reprint requests to Dr. Halpern at the Perelman School of Medicine, University of Pennsylvania, 719 Blockley Hall, 423 Guardian Dr., Philadelphia, PA 19104-6021, or at shalpern@ exchange.upenn.edu.

This article was published on May 13, 2015, at NEJM.org.

N EnglJ Med 2015;372:2108-17. DOI: 10.1056/NEJMoal414293

Copyright $\odot 2015$ Massachusetts Medical Society.
A BSTRACT

BACKGROUND

Financial incentives promote many health behaviors, but effective ways to deliver health incentives remain uncertain.

METHODS

We randomly assigned CVS Caremark employees and their relatives and friends to one of four incentive programs or to usual care for smoking cessation. Two of the incentive programs targeted individuals, and two targeted groups of six participants. One of the individual-oriented programs and one of the group-oriented programs entailed rewards of approximately $\$ 800$ for smoking cessation; the others entailed refundable deposits of $\$ 150$ plus $\$ 650$ in reward payments for successful participants. Usual care included informational resources and free smokingcessation aids.

\section{RESULTS}

Overall, 2538 participants were enrolled. Of those assigned to reward-based programs, $90.0 \%$ accepted the assignment, as compared with $13.7 \%$ of those assigned to deposit-based programs $(\mathrm{P}<0.001)$. In intention-to-treat analyses, rates of sustained abstinence from smoking through 6 months were higher with each of the four incentive programs (range, 9.4 to $16.0 \%)$ than with usual care $(6.0 \%)(\mathrm{P}<0.05$ for all comparisons); the superiority of reward-based programs was sustained through 12 months. Group-oriented and individual-oriented programs were associated with similar 6-month abstinence rates $(13.7 \%$ and $12.1 \%$, respectively; $\mathrm{P}=0.29)$. Reward-based programs were associated with higher abstinence rates than deposit-based programs $(15.7 \%$ vs. $10.2 \%, \mathrm{P}<0.001)$. However, in instrumental-variable analyses that accounted for differential acceptance, the rate of abstinence at 6 months was 13.2 percentage points $(95 \%$ confidence interval, 3.1 to 22.8) higher in the deposit-based programs than in the reward-based programs among the estimated $13.7 \%$ of the participants who would accept participation in either type of program.

CONCLUSIONS

Reward-based programs were much more commonly accepted than deposit-based programs, leading to higher rates of sustained abstinence from smoking. Grouporiented incentive programs were no more effective than individual-oriented programs. (Funded by the National Institutes of Health and CVS Caremark; ClinicalTrials.gov number, NCT01526265.) 
$\mathrm{F}$ INANCIAL INCENTIVES HAVE BEEN SHOWN to promote a variety of health behaviors. ${ }^{1-8}$ For example, in a randomized, clinical trial involving 878 General Electric employees, a bundle of incentives worth $\$ 750$ for smoking cessation nearly tripled quit rates, from $5.0 \%$ to $14.7 \%,{ }^{8}$ and led to a program adapted by General Electric for its U.S. employees. ${ }^{9}$ Although incentive programs are increasingly used by governments, employers, and insurers to motivate changes in health behavior, ${ }^{10,11}$ their design is usually based on the traditional economic assumption that the size of the incentive determines its effectiveness. In contrast, behavioral economic theory suggests that incentives of similar size may have very different effects depending on how they are designed. ${ }^{12}$

For example, deposit or "commitment" contracts, whereby participants put some of their own money at risk and recoup it if they are successful in changing their behavior, have been used in a variety of online and employer-based behavioral-change programs. Because people are typically more motivated to avoid losses than to seek gains, ${ }^{13}$ deposit contracts should be more successful than reward programs. However, the need to make deposits may deter people from participating, and the overall effectiveness of deposit and reward programs has not been compared. ${ }^{14,15}$

Furthermore, incentives that target groups may be more effective than incentives that target individuals because people are strongly motivated by social comparisons. ${ }^{16-18}$ Collaborative incentives, whereby payments to successful group members increase with the overall success of the group, may add dimensions of interpersonal accountability and teamwork. ${ }^{19}$ Competitive designs, such as pari-mutuel schemes in which money deposited by group members who do not change their behavior gets distributed to group members who do, may amplify peoples' aversions to loss by highlighting the regret they may feel if others benefit from their failure to change. ${ }^{20,21}$

We therefore evaluated incentive programs for smoking cessation that are based on rewards or deposit contracts and that are delivered at the individual or group level, comparing the interventions on three measures: acceptance, defined as the proportion of people who accept the incentive program when offered; overall effectiveness, assessed as the proportion of people offered each program who stop smoking; and efficacy, assessed as the proportion of people who stop smoking if they accept a given incentive program.

\section{METHODS}

\section{TRIAL DESIGN}

We conducted a five-group randomized, controlled trial comparing usual care with four incentive programs aimed at promoting sustained abstinence from smoking. The protocol (available with the full text of this article at NEJM.org) was approved by the institutional review board at the University of Pennsylvania. The first author vouches for the accuracy and completeness of the data and for the fidelity of the study to the protocol.

\section{STUDY POPULATION}

We used a multifaceted recruitment scheme (Fig. S1 in the Supplementary Appendix, available at NEJM.org) to enroll CVS Caremark employees or their relatives and friends across the United States. Eligible participants were at least 18 years of age, reported smoking at least 5 cigarettes per day, had Internet access, and indicated an interest in learning about ways to stop smoking. Recruitment occurred from February 2012 through October 2012. Using the Way to Health Web-based research portal created for this and other studies, ${ }^{22}$ participants opened an account, electronically signed the informedconsent document, and completed a baseline questionnaire. Participants were told that they would be paid for completing questionnaires and submitting samples to confirm smoking abstinence and that the study tested different ways of providing financial incentives to promote cessation. To dissuade nonsmokers from enrolling, we also informed potential participants that we would randomly screen for baseline smoking.

After randomization, participants learned the details of their assigned intervention, were asked to accept or decline their intervention, and chose a target quit date between 1 and 90 days after enrollment. We then selected a random sample of $5 \%$ of these enrolled participants to undergo baseline cotinine screening and offered $\$ 100$ for completing a cotinine assay. 


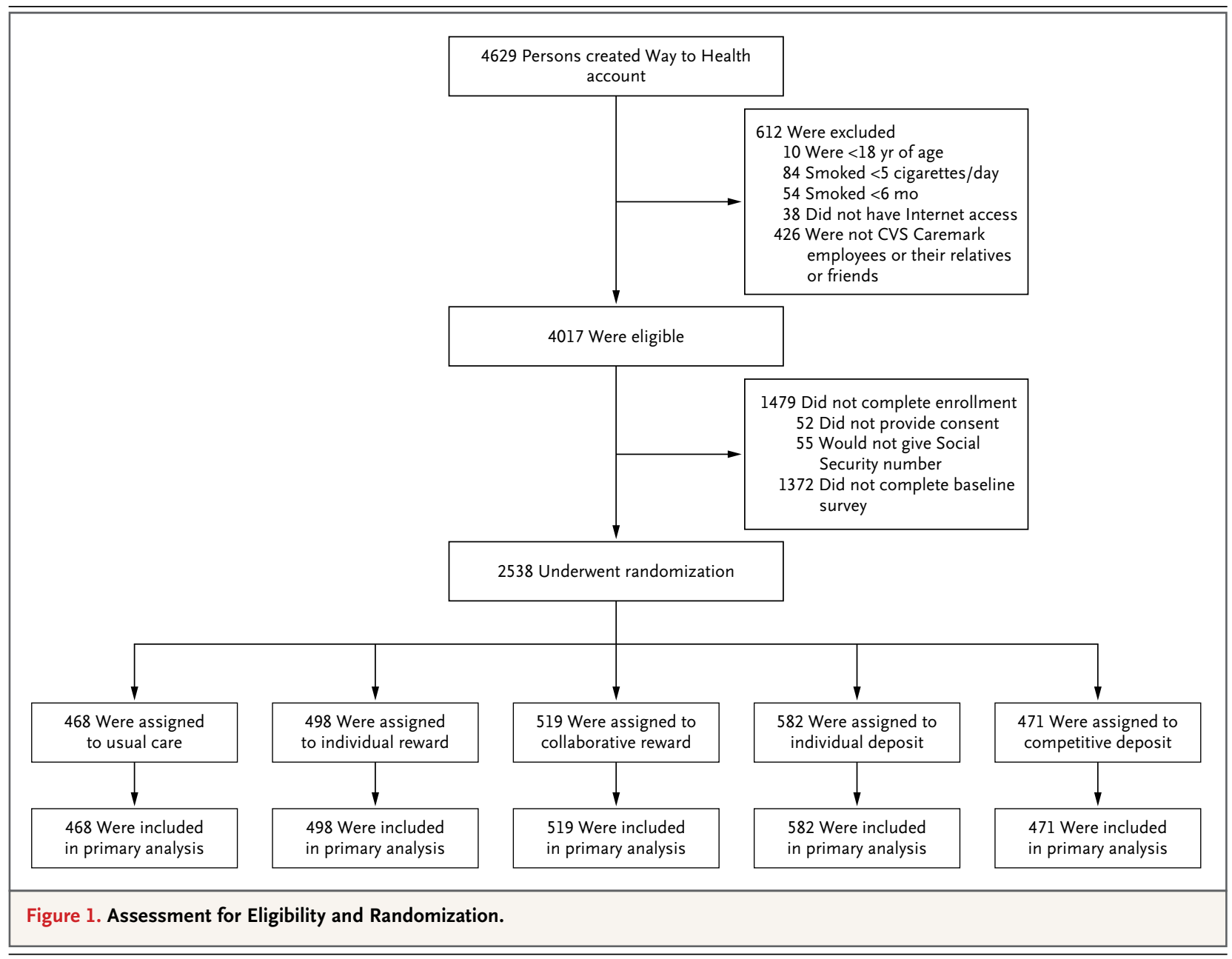

RANDOMIZATION AND INTERVENTIONS

Participants were randomly assigned on an individual basis to one of five groups (Fig. 1). Randomization was stratified according to two dichotomous variables: whether participants had full health care benefits through CVS Caremark and whether their annual household income was at least $\$ 60,000$ (the CVS Caremark workforce median) or less than $\$ 60,000$. We developed an adaptive randomization algorithm ${ }^{23-26}$ that updated the assignment probabilities to the five groups after every third enrolled participant. Updated probabilities reflected the inverse of the proportion of participants assigned to that group who accepted the intervention, relative to total acceptance across groups. ${ }^{26}$ This approach balances recruitment of accepting participants across groups by increasing the odds of randomization to interventions that previous participants declined.
All the participants were offered usual care, consisting of information about local smokingcessation resources, cessation guides produced by the American Cancer Society, and, for the $41 \%$ of the participants receiving health benefits through CVS Caremark, free access to a behavioral-modification program and nicotine-replacement therapy. Participants assigned to the two individual-incentive groups were also eligible to receive $\$ 200$ if they had biochemically confirmed abstinence at each of three times: 14 days, 30 days, and 6 months after their target quit dates. Participants would get an additional $\$ 200$ bonus at 6 months, for a total of $\$ 800$ (Fig. S2 in the Supplementary Appendix). In the individual-deposit group, this sum included a $\$ 150$ deposit that would be refunded to participants who quit smoking.

In the collaborative-reward and competitivedeposit groups, cohorts of six smokers each were formed on a rolling basis, linking participants 
who selected quit dates nearest each other. In the collaborative-reward group, payments to successful group members at each time point increased with increasing group success rates, from $\$ 100$ per time point if one participant quit to $\$ 600$ per time point per participant if all six quit. We sought to foster collaboration among participants with the use of a Web-based chat room through which they could communicate throughout the study.

In the competitive-deposit group, $\$ 150$ deposits from each of six group members, plus a $\$ 450$ matching reward per member $(\$ 3,600$ total), was redistributed among members who quit at each time point. For example, if only two participants in a group quit at 14 days but returned to smoking by 30 days, those two participants would receive $\$ 600$ each at 14 days, and there would be no further payouts to the members of that group. Members of competitive cohorts received accurate but anonymous descriptions of their competitors to make vivid the possibility that others might benefit from their own lack of change ${ }^{21}$ without enabling participants to undermine a competitor's efforts.

Participants in the group-incentive groups were also given a $\$ 200$ bonus if they sustained abstinence through 6 months. Thus, the four interventions differed in how incentives would accrue and be disbursed (Fig. S2 in the Supplementary Appendix), but the payment schedule and bonus were identical, and on the basis of anticipated success rates, we estimated that each intervention carried an expected value of $\$ 800$.

\section{OUTCOMES}

The primary outcome was sustained abstinence from smoking for 6 months after the target quit date. ${ }^{27}$ Achievement of sustained abstinence required that submitted saliva samples had a cotinine concentration of less than $10 \mathrm{ng}$ per milliliter ${ }^{28}$ at 14 days, 30 days, and 6 months. For users of nicotine-replacement therapy, a urinary sample with an anabasine concentration of less than 3 ng per milliliter was considered to show sustained abstinence. ${ }^{29}$ Participants who did not submit samples were coded as actively smoking. Secondary outcomes included the initial quit rate at 14 days, sustained abstinence for 30 days, and sustained abstinence through 12 months (i.e., 6 months after the final incentive disbursement).
Incentive acceptance rates reflected the proportion of participants assigned to that incentive who agreed to the contract. In the two groups requiring deposits, we considered participants to have accepted the intervention if they made $\$ 150$ deposits by credit or debit card within 60 days after enrollment or before their selected quit date, whichever came first. Consenting participants who declined their assigned program remained in their assigned group for intentionto-treat analyses and were treated identically to those in the usual-care group.

\section{STATISTICAL ANALYSIS}

We specified three analyses corresponding to the aims of the study. First, we used logistic regression to compare acceptance of the interventions, adjusting for the two variables according to which the randomization was stratified. $.^{30} \mathrm{Sec}-$ ond, we conducted intention-to-treat analyses using logistic regression to compare the effectiveness of incentive programs among all randomly assigned participants. Third, we compared the efficacy of the interventions. We first conducted traditional per-protocol analyses, comparing groups of participants who accepted different interventions. However, because such analyses are subject to selection biases, ${ }^{31}$ our primary approach to measure efficacy modeled the randomization group as an instrumental variable $^{32,33}$ in analyses of the complier average treatment effect. ${ }^{34-36}$ These analyses, described in detail in the Supplementary Appendix, used data on all randomly assigned participants to estimate treatment effects for participants who would have accepted each intervention.

We estimated that a sample of 2185 participants would provide $80 \%$ power to detect absolute differences of at least 7.5 percentage points in the rate of sustained abstinence between any one of the three novel incentive programs and the individual-reward program. Details of this calculation are provided in the Supplementary Appendix.

\section{RESULTS}

\section{PATIENT CHARACTERISTICS}

Overall, 2538 participants were enrolled. The demographic and smoking-related characteristics of the participants were balanced across the five study groups (Table 1). 


\begin{tabular}{|c|c|c|c|c|c|}
\hline Characteristic & $\begin{array}{c}\text { Usual Care } \\
(\mathrm{N}=468)\end{array}$ & $\begin{array}{l}\text { Individual } \\
\text { Reward } \\
(N=498)\end{array}$ & $\begin{array}{c}\text { Collaborative } \\
\text { Reward } \\
(N=519)\end{array}$ & $\begin{array}{c}\text { Individual } \\
\text { Deposit } \\
(N=582)\end{array}$ & $\begin{array}{c}\text { Competitive } \\
\text { Deposit } \\
(\mathrm{N}=471)\end{array}$ \\
\hline \multicolumn{6}{|l|}{ Demographic characteristics } \\
\hline \multicolumn{6}{|l|}{ Age $-y r$} \\
\hline Median & 34 & 32 & 32 & 33 & 33 \\
\hline Interquartile range & $26-47$ & $25-46$ & $25-45$ & $25-48$ & $25-45$ \\
\hline Female sex — no. (\%) & $300(64)$ & $312(63)$ & $322(62)$ & $367(63)$ & $293(62)$ \\
\hline \multicolumn{6}{|l|}{ Race-no. (\%)† } \\
\hline White & $365(78)$ & $409(82)$ & $387(75)$ & $452(78)$ & $376(80)$ \\
\hline Black & $43(9)$ & $44(9)$ & $58(11)$ & $54(9)$ & $49(10)$ \\
\hline Other & $60(13)$ & $45(9)$ & $74(14)$ & $76(13)$ & $46(10)$ \\
\hline \multicolumn{6}{|l|}{ Years of education } \\
\hline Median & 13 & 13 & 13 & 13 & 13 \\
\hline Interquartile range & $12-14$ & $12-14$ & $12-15$ & $12-15$ & $12-15$ \\
\hline \multicolumn{6}{|l|}{ Annual household income - no. (\%) } \\
\hline$<\$ 60,000$ & $346(74)$ & $375(75)$ & $382(74)$ & $403(69)$ & $358(76)$ \\
\hline$\geq \$ 60,000$ & $122(26)$ & $123(25)$ & $137(26)$ & $179(31)$ & $113(24)$ \\
\hline \multicolumn{6}{|l|}{ Health insurance - no. (\%) $\mathbb{R}$} \\
\hline \multicolumn{6}{|l|}{ CVS Caremark employee } \\
\hline Enrolled in CVS Caremark health care plan & $152(32)$ & $174(35)$ & $177(34)$ & $213(37)$ & $168(36)$ \\
\hline Not enrolled in CVS Caremark health care plan & $139(30)$ & $136(27)$ & $151(29)$ & $180(31)$ & $146(31)$ \\
\hline \multicolumn{6}{|l|}{ Relative or friend of CVS Caremark employee } \\
\hline Enrolled in CVS Caremark health care plan & $36(8)$ & $33(7)$ & $26(5)$ & $29(5)$ & $36(8)$ \\
\hline Not enrolled in CVS Caremark health care plan & $141(30)$ & $155(31)$ & $165(32)$ & $160(27)$ & $121(26)$ \\
\hline \multicolumn{6}{|l|}{ Smoking history } \\
\hline \multicolumn{6}{|l|}{ No. of cigarettes smoked per day } \\
\hline Median & 15 & 15 & 15 & 15 & 15 \\
\hline Interquartile range & $10-20$ & $10-20$ & $9-20$ & $10-20$ & $10-20$ \\
\hline \multicolumn{6}{|l|}{ Duration of regular smoking $-\mathrm{yr}$} \\
\hline Median & 15 & 12 & 13 & 14 & 14 \\
\hline Interquartile range & $6-26$ & $6-25$ & $6-25$ & $6-25$ & $7-25$ \\
\hline \multicolumn{6}{|l|}{ Age at first smoking $-\mathrm{yr}$} \\
\hline Median & 17 & 17 & 17 & 17 & 17 \\
\hline Interquartile range & $15-19$ & $15-19$ & $15-19$ & $15-19$ & $15-19$ \\
\hline \multicolumn{6}{|l|}{ Level of nicotine dependence - no. (\%) 9} \\
\hline Low & $101(22)$ & $111(22)$ & $118(23)$ & $122(21)$ & $95(20)$ \\
\hline Low to moderate & $148(32)$ & $155(31)$ & $152(29)$ & $185(32)$ & $141(30)$ \\
\hline Moderate & $194(41)$ & $210(42)$ & $229(44)$ & $251(43)$ & $215(46)$ \\
\hline High & $25(5)$ & $22(4)$ & $20(4)$ & $24(4)$ & $20(4)$ \\
\hline \multicolumn{6}{|l|}{ Stage of change - no. (\%)\| } \\
\hline Preparation & $300(64)$ & $312(63)$ & $327(63)$ & $372(64)$ & $312(66)$ \\
\hline Contemplation & $168(36)$ & $186(37)$ & $192(37)$ & $210(36)$ & $158(34)$ \\
\hline Successfully quit for a $24-\mathrm{hr}$ period in past year - no. (\%) & $300(64)$ & $307(62)$ & $328(63)$ & $361(62)$ & $294(62)$ \\
\hline
\end{tabular}




\begin{tabular}{|c|c|c|c|c|c|}
\hline Characteristic & $\begin{array}{l}\text { Usual Care } \\
(\mathrm{N}=468)\end{array}$ & $\begin{array}{c}\text { Individual } \\
\text { Reward } \\
(\mathrm{N}=498)\end{array}$ & $\begin{array}{l}\text { Collaborative } \\
\text { Reward } \\
(\mathrm{N}=519)\end{array}$ & $\begin{array}{l}\text { Idividual } \\
\text { Deposit } \\
N=582 \text { ) }\end{array}$ & $\begin{array}{l}\text { Competitive } \\
\text { Deposit } \\
(\mathrm{N}=471)\end{array}$ \\
\hline Ever used NRT or assistance to quit smoking — no. (\%) & $340(73)$ & $384(77)$ & $384(74)$ & $421(72)$ & $350(74)$ \\
\hline Currently using other methods to quit smoking — no. (\%)*** & $65(14)$ & $51(10)$ & $71(14)$ & $73(13)$ & $47(10)$ \\
\hline \multicolumn{6}{|c|}{$\begin{array}{l}\text { The intention-to-treat population includes all participants who underwent randomization to the five study groups. There were no sig- } \\
\text { nificant differences between the study groups in any of the baseline characteristics listed (P>0.05). NRT denotes nicotine-replacement } \\
\text { therapy. } \\
\text { Race was self-reported. } \\
\text { Years of education range from grade } 1 \text { to } 17 \text {, with } 17 \text { representing "at least some graduate school" and } 13 \text { to } 16 \text { representing } 1 \text { to } 4 \text { years } \\
\text { of college. } \\
\text { The CVS Caremark health care plan includes free access to a behavioral-modification program and NRT. } \\
\text { The level of dependence is based on the score on the Fagerström Test for Nicotine Dependence. Scores range from } 1 \text { to } 10 \text {, with higher } \\
\text { scores indicating a more intense physical dependence on nicotine. Low dependence corresponds to a score of } 1 \text { or } 2 \text {, low-to-moderate de- } \\
\text { pendence a score of } 3 \text { or } 4 \text {, moderate dependence a score of } 5 \text { to } 7 \text {, and high dependence a score of } 8 \text { to } 10 \text {. } \\
\text { The participants were asked, "Are you seriously thinking of quitting smoking?" and were given three options to select: yes, within the next } \\
30 \text { days (preparation stage); yes, within the next } 6 \text { months (contemplation stage); or no, not thinking of quitting (precontemplation } \\
\text { stage). The values for contemplation stage include } 10 \text { participants in the precontemplation stage: } 2 \text { participants in the usual-care group, } \\
2 \text { participants in the individual-reward group, } 2 \text { participants in the collaborative-reward group, } 3 \text { participants in the individual-deposit group, } \\
\text { and } 1 \text { participant in the competitive-deposit group. Data were missing for } 1 \text { participant in the competitive-deposit group. } \\
\text { Participant is currently using NRT, behavioral therapy, prescription medication, or other method to quit smoking. }\end{array}$} \\
\hline
\end{tabular}

\section{ACCEPTANCE OF INTERVENTIONS}

Of 2070 participants assigned to one of the four intervention groups, 1060 (51.2\%) accepted that intervention. Participants were much more likely to accept the two reward-based incentive programs (combined acceptance rate, $90.0 \%$ ) than the two deposit-based programs (combined acceptance rate, 13.7\%) $(\mathrm{P}<0.001)$ (Fig. 2). Participants were similarly likely to accept the individual incentives (combined acceptance rate, 50.6\%) and the group incentives (combined acceptance rate, $51.9 \%)(\mathrm{P}=0.55)$.

\section{EFFECTIVENESS AND COSTS OF INTERVENTIONS}

Median payouts to participants who stopped smoking in the four incentive groups were similar (Table S1 in the Supplementary Appendix). In intention-to-treat analyses, all four programs yielded greater rates of sustained abstinence from smoking through 6 months (range, 9.4 to $16.0 \%)$ than did usual care $(6.0 \%)(\mathrm{P}<0.05$ for all comparisons) (Fig. 3, and Table S2 in the Supplementary Appendix). At 12 months (6 months after the cessation of incentives), roughly half the participants who were abstinent through 6 months in all groups submitted negative cotinine assays, and only the reward-based incentive programs remained superior to usual care (Fig. 3). The proportion of self-reported quitters who submitted a cotinine sample was lower at 12 months than at 30 days or 6 months in all groups (Table S3 in the Supplementary Appendix). In secondary analyses of self-reported abstinence at 12 months, relapsed smoking was much less common than in analyses requiring biochemical confirmation, and all incentive groups remained superior to usual care (Table S2 in the Supplementary Appendix).

At 6 months, the proportion of participants with sustained abstinence was greater with reward-based incentives (15.7\%) than with depositbased incentives $(10.2 \%)(\mathrm{P}<0.001)$ (Table S4 in the Supplementary Appendix) and was similar between participants assigned to individualincentive programs and those assigned to groupincentive programs $(12.1 \%$ vs. $13.7 \%, \mathrm{P}=0.29)$ (Table S5 in the Supplementary Appendix). Participants with access to free pharmacologic cessation aids through their CVS Caremark benefits did not have higher abstinence rates than participants without such benefits (Table S6 in the Supplementary Appendix). Total costs spent per participant who had sustained abstinence were lower in the deposit-based groups than in the reward-based groups (Fig. S3 in the Supplementary Appendix).

\section{EFFICACY OF INTERVENTIONS}

Given the similar effectiveness of individual rewards and collaborative rewards and of individ- 


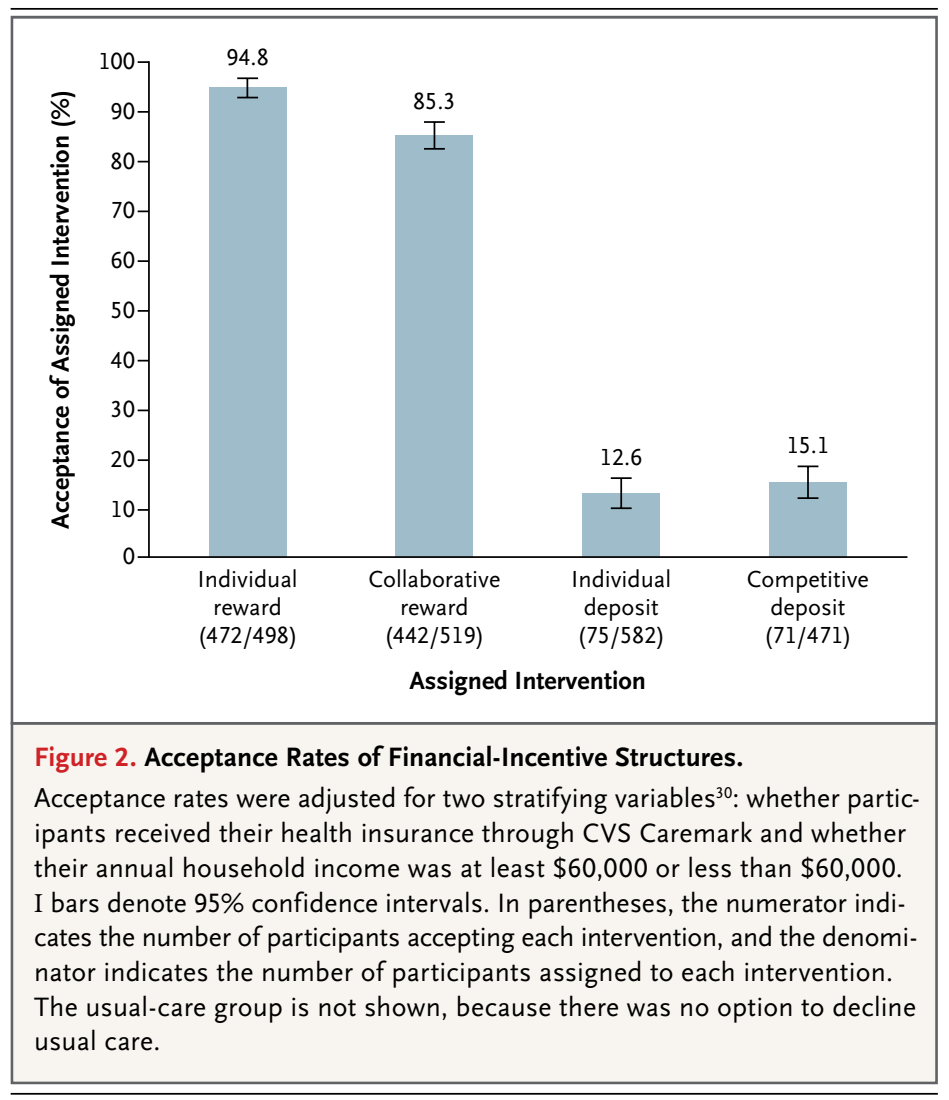

ual deposits and competitive deposits, we grouped the reward-based incentives as well as the deposit-based incentives for efficacy analyses. In standard per-protocol analyses, 52.3\% of those who accepted deposits versus $17.1 \%$ of those who accepted rewards had sustained abstinence through 6 months $(\mathrm{P}<0.001)$, and similarly large differences were observed at all time points (Table S7 in the Supplementary Appendix). In analyses of the complier average treatment effect, which adjust for the selection effects inherent in per-protocol analyses, the rate of abstinence at 6 months was 13.2 percentage points $(95 \%$ confidence interval, 3.1 to 22.8) higher in the deposit-based programs than in the reward-based programs among the $13.7 \%$ of smokers who would accept either type of incentive (Table 2). According to this approach, deposits were superior to rewards even if we assumed that participants who would accept deposits had up to 12.5 times greater underlying propensities to stop smoking than participants who would accept rewards only.

\section{ANALYSES ACCOUNTING FOR ENROLLMENT} OF POTENTIAL NONSMOKERS

Among 150 participants asked to submit a cotinine assay at baseline to confirm smoking status, $9(6.0 \%)$ submitted negative assays and 21 $(14.0 \%)$ did not return assays. These rates were similar across groups (Table S8 in the Supplementary Appendix), and sensitivity analyses adjusting for the possibility that up to $20 \%$ of the participants were not smokers revealed nearly identical estimates of effectiveness (Table S9 in the Supplementary Appendix).

\section{SCUSSION}

More than 50 years after the release of the first Surgeon General's report on the harmful effects of smoking, national policies, behavioral programs, and pharmacologic approaches have helped reduce smoking rates in the United States. ${ }^{37}$ However, the need for new approaches is clear because smoking remains the leading cause of preventable illness and death. ${ }^{38,39}$

In this large randomized trial across the United States, we found that four different incentive programs with expected values of $\$ 800$ were each effective in promoting sustained abstinence from smoking. Perhaps the most important finding is that incentive programs that required people to deposit $\$ 150$ of their own money were less effective overall than rewardbased programs of similar value because few people accepted such deposit programs. This was true despite the $\$ 650$ reward offered to depositarm participants in addition to the return of their original \$150 deposits. However, analyses that account for the different acceptance rates of the interventions showed that deposit-based incentives were substantially more efficacious than reward-based incentives among people who would have accepted either. The robustness of this result to reasonably large potential selection effects suggests that incentives that build on participants' loss aversion ${ }^{13}$ may meaningfully change behavior.

Second, we found that group-oriented reward programs were not significantly more effective than individual-oriented programs. The results of this large trial are therefore consistent with those of small randomized, controlled trials of incentives for weight loss in which group-oriented 
payments, as compared with individual-oriented payments, produced small early benefits that were not sustained over time. ${ }^{19,22}$

Finally, the finding that individual rewards of $\$ 800$, as compared with usual care, nearly tripled the rate of smoking cessation among CVS Caremark employees and their friends and family confirms and extends the generalizability of our finding from a previous trial involving General Electric employees. ${ }^{8}$ In addition to the public health effects of such smoking reductions, these findings are important for employers. Because employing a smoker is estimated to cost $\$ 5,816$ more each year than employing a nonsmoker, ${ }^{40}$ even an $\$ 800$ payment borne entirely by employers and paid only to those who quit would be highly cost-saving.

This study has limitations. First, the low rate of acceptance of the deposit programs required protocol modifications to restrict the proportions of participants who would be randomly assigned to those groups. Implementing these limitations preserved balance in participant characteristics across groups and preserved power for all effectiveness analyses but limited the precision of analyses comparing the efficacy of reward and deposit groups. Second, only $41 \%$ of the participants had access to free pharmacologic and behavioral cessation aids through their employee benefits. However, smoking-cessation rates were not higher among those with access to such aids, a finding that suggests that the superiority of incentives would hold in populations with universal access. Third, in all trial groups, nearly half the smokers who quit at the end of the intervention at 6 months did not document sustained abstinence through 12 months. This suggests similar durability of financial incentives to nicotine-replacement therapy and bupropion, for which relapse after completion of treatment has also occurred in roughly $50 \%$ of the participants. ${ }^{41,42}$ Secondary analyses suggest that the true relapse rates in our trial may have been lower, given the reduction in submission of any samples at 12 months across groups (Table S3 in the Supplementary Appendix).

This study also has several strengths. In addition to comparing financial incentives for smoking cessation in a large number of partici-

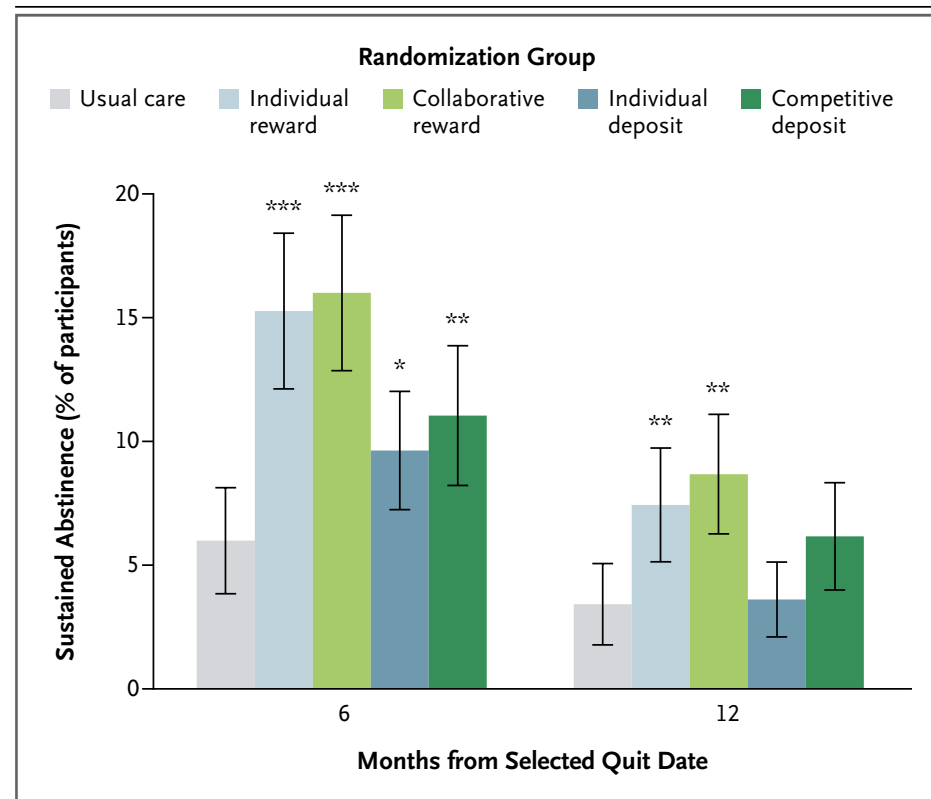

Figure 3. Rates of Sustained Abstinence from Smoking at 6 and 12 Months after Target Quit Date.

The primary outcome was sustained abstinence through 6 months. Asterisks indicate $P$ values (* for $P<0.05$, $* *$ for $P<0.01$, and $* * *$ for $P<0.001$ ) for the comparison of the four intervention groups to usual care, with adjustment for the two stratifying variables ${ }^{30}$ : whether participants received their health insurance through CVS Caremark and whether their annual household income was at least $\$ 60,000$ or less than $\$ 60,000$. I bars indicate $95 \%$ confidence intervals.

pants, the trial measured the specific contributions of acceptance and efficacy of the interventions to their overall effectiveness. This trial also compared multiple incentive programs with design features based on behavioral economic theory, including repeated payments to reinforce target behaviors ${ }^{43}$ bonus payments at the end of the intervention to offset smokers' tendencies to discount the importance of future events, ${ }^{44,45}$ and the provision of ongoing feedback regarding participants' accrued gains and losses contingent on their self-reported smoking status to maximize the effect of regret aversion. ${ }^{20,21}$ Finally, this trial randomly selected participants for screening cotinine tests to prevent nonsmokers from enrolling. The robustness of our findings in analyses accounting for potential participation of nonsmokers provides strong evidence regarding the effectiveness of incentives. 
Table 2. Analysis of the Complier Average Treatment Effect of Sustained Abstinence from Smoking at 6 Months.*

Comparison of Efficacy

Reward-based incentives vs. usual care among participants who would accept reward incentive

Deposit-based incentives vs. usual care among participants who would accept deposit incentive

Deposit-based incentives $\dagger$ vs. reward-based incentives among participants who would accept either type of incentive, with the assumption that the underlying odds of quitting among participants who would accept deposits are greater than the odds of quitting among participants who would only accept rewards by a factor of

2.71, the lower boundary of the $95 \% \mathrm{Cl}$ of the best estimate

9.36, the best estimate

23.12 , the upper boundary of the $95 \% \mathrm{Cl}$ of the best estimate

\section{Absolute Difference in Rate} of Sustained Abstinence

percentage points $(95 \% \mathrm{Cl})$

10.7 (6.8 to 14.7$)$

30.8 (11.0 to 50.6$)$

25.8 (16.2 to 34.8$)$

13.2 (3.1 to 22.8 )

$6.4(-5.7$ to 17.4$)$

* A detailed explanation of this analysis is provided in the Supplementary Appendix. In brief, this method uses the randomization group as an instrumental variable, thereby providing estimates of the efficacy of interventions among people who accept them. Unlike traditional per-protocol analyses, this approach uses data on all randomly assigned participants and adjusts estimates of efficacy for the selection biases that may arise if participants' decisions to accept or decline their assigned interventions are related to their underlying odds of smoking cessation. ${ }^{34-36}$ This analysis assumes that participants who would accept deposits would have also accepted rewards if rewards had instead been offered. Estimates are on the additive scale; thus, absolute risk differences are shown with $95 \%$ confidence intervals (Cls).

$\uparrow$ The efficacy of deposit contracts is statistically superior to the efficacy of rewards as long as the underlying odds of quitting among participants who accept deposits are no more than 12.5 times greater than the odds of quitting among participants who would only accept rewards.

In summary, this trial shows that among several financial-incentive programs for smoking cessation, rewards for smoking cessation are more effective overall than are deposit-based contracts owing to their much higher rate of acceptance. In addition, the efficacy of depositbased contracts among those who use them and the cost-effectiveness of such contracts for employers suggest that future innovations in em- ployee benefit design should seek to establish the effectiveness of smoking-cessation programs requiring deposits smaller than the $\$ 150$ used in this trial.

Supported by a grant from the National Cancer Institute (R01 CA159932, to Dr. Halpern), a grant from the National Institute on Aging (RC2 AG036592, to Drs. Asch and Volpp), and CVS Caremark.

Disclosure forms provided by the authors are available with the full text of this article at NEJM.org.
REFERENCES

1. Higgins ST, Budney AJ, Bickel WK, Foerg FE, Donham R, Badger GJ. Incentives improve outcome in outpatient behavioral treatment of cocaine dependence. Arch Gen Psychiatry 1994;51:568-76.

2. Kane RL, Johnson PE, Town RJ, Butler M. A structured review of the effect of economic incentives on consumers' preventive behavior. Am J Prev Med 2004;27: 327-52.

3. Lussier JP, Heil SH, Mongeon JA, Badger GJ, Higgins ST. A meta-analysis of voucher-based reinforcement therapy for substance use disorders. Addiction 2006; 101:192-203.

4. Volpp KG, John LK, Troxel AB, Norton L, Fassbender J, Loewenstein G. Financial incentive-based approaches for weight loss: a randomized trial. JAMA 2008;300: 2631-7.

5. Volpp KG, Loewenstein G, Troxel AB, et al. A test of financial incentives to improve warfarin adherence. BMC Health Serv Res 2008;8:272.

6. Giuffrida A, Torgerson DJ. Should we pay the patient? Review of financial incentives to enhance patient compliance. BMJ 1997;315:703-7.

7. Sutherland K, Christianson JB, Leatherman S. Impact of targeted financial incentives on personal health behavior: a review of the literature. Med Care Res Rev 2008; 65:Suppl:36S-78S.

8. Volpp KG, Troxel AB, Pauly MV, et al. A randomized, controlled trial of financial incentives for smoking cessation. $\mathrm{N}$ Engl J Med 2009;360:699-709.

9. Volpp KG, Galvin R. Reward-based incentives for smoking cessation: how a carrot became a stick. JAMA 2014;311: 909-10.

10. Strickland S. Does it work to pay peo- ple to live healthier lives? BMJ 2014;348: g2458.

11. Towers Watson National Business Group on Health. Employer survey on purchasing value in health care, 2014 (http://www.towerswatson.com/en-US/ Insights/IC-Types/Survey-Research-Results/ 2014/05/full-report-towers-watson-nbgh -2013-2014-employer-survey-on-purchasing -value-in-health-care).

12. Volpp KG, Pauly MV, Loewenstein G, Bangsberg D. P4P4P: an agenda for research on pay-for-performance for patients. Health Aff (Millwood) 2009;28:206-14.

13. Kahneman D, Tversky A. Prospect theory: an analysis of decision under risk. Econometrica 1979;47:263-91.

14. Halpern SD, Asch DA, Volpp KG. Commitment contracts as a way to health. BMJ 2012;344:e522.

15. Rogers T, Milkman KL, Volpp KG. 
Commitment devices: using initiatives to change behavior. JAMA 2014;311:2065-6. 16. Christakis NA, Fowler JH. The collective dynamics of smoking in a large social network. N Engl J Med 2008;358:2249-58. 17. Watts DJ, Strogatz SH. Collective dynamics of 'small-world' networks. Nature 1998;393:440-2.

18. Paul-Ebhonhimhen V, Avenell A. A systematic review of the effectiveness of group versus individual treatments for adult obesity. Obes Facts 2009;2:17-24.

19. Jeffery RW, Gerber WM, Rosenthal BS, Lindquist RA. Monetary contracts in weight control: effectiveness of group and individual contracts of varying size. J Consult Clin Psychol 1983;51:242-8.

20. Connolly T, Butler DU. Regret in economic and psychological theories of choice. J Behav Decis Mak 2006;19:148-58.

21. Hoelzl E, Loewenstein G. Wearing out your shoes to prevent someone else from stepping into them: anticipated regret and social takeover in sequential decisions. Organ Behav Hum Decis Process 2005;98:15-27.

22. Kullgren JT, Troxel AB, Loewenstein $\mathrm{G}$, et al. Individual- versus group-based financial incentives for weight loss: a randomized, controlled trial. Ann Intern Med 2013;158:505-14

23. Hu FF, Zhang LX, He XM. Efficient randomized-adaptive designs. Ann Statist 2009;37:2543-60.

24. Dragalin V. Adaptive designs: terminology and classification. Drug Inf J 2006; 40:425-35.

25. Brown $\mathrm{CH}$, Ten Have TR, Jo B, et al. Adaptive designs for randomized trials in public health. Annu Rev Public Health 2009;30:1-25.

26. French B, Small DS, Novak J, et al. Preference-adaptive randomization in comparative effectiveness studies. Trials 2015; 16:99.

27. Hughes JR, Keely JP, Niaura RS, Ossip-
Klein DJ, Richmond RL, Swan GE. Measures of abstinence in clinical trials: issues and recommendations. Nicotine Tob Res 2003;5:13-25.

28. Benowitz NL, Ahijevch K, Hall S, et al. Biochemical verification of tobacco use and cessation. Nicotine Tob Res 2002;4: 149-59.

29. Jacob P III, Hatsukami D, Severson H, Hall S, Yu L, Benowitz NL. Anabasine and anatabine as biomarkers for tobacco use during nicotine replacement therapy. Cancer Epidemiol Biomarkers Prev 2002; 11:1668-73.

30. Kahan BC, Morris TP. Improper analysis of trials randomised using stratified blocks or minimisation. Stat Med 2012; 31:328-40.

31. Sommer A, Zeger SL. On estimating efficacy from clinical trials. Stat Med 1991;10:45-52

32. Newhouse JP, McClellan M. Econometrics in outcomes research: the use of instrumental variables. Annu Rev Public Health 1998;19:17-34.

33. Angrist JD, Imbens GW, Rubin DB. Identification of causal effects using instrumental variables. J Am Stat Assoc 1996;91:444-55.

34. Sussman JB, Hayward RA. An IV for the RCT: using instrumental variables to adjust for treatment contamination in randomised controlled trials. BMJ 2010; 340:c2073.

35. Cheng J, Small D. Bounds on causal effects in three-arm trials with noncompliance. J R Stat Soc B 2006;68:815-36.

36. Cheng J, Small D, Tan Z, Ten Have T. Efficient nonparametric estimation of causal effects in randomized trials with noncompliance. Biometrika 2009;96:1936

37. The health consequences of smoking - 50 years of progress: a report of the Surgeon General. Atlanta: Department of Health and Human Services, Centers for
Disease Control and Prevention, National Center for Chronic Disease Prevention and Health Promotion, Office on Smoking and Health, 2014 (http://www.surgeongeneral .gov/library/reports/50-years-of-progress/ full-report.pdf).

38. Rostron BL, Chang CM, Pechacek TF. Estimation of cigarette smoking-attributable morbidity in the United States. JAMA Intern Med 2014;174:1922-8.

39. Danaei G, Ding EL, Mozaffarian D, et al. The preventable causes of death in the United States: comparative risk assessment of dietary, lifestyle, and metabolic risk factors. PLoS Med 2009;6(4):e1000058.

40. Berman M, Crane R, Seiber E, Munur $M$. Estimating the cost of a smoking employee. Tob Control 2014;23:428-33.

41. Jorenby DE, Leischow SJ, Nides MA, et al. A controlled trial of sustained-release bupropion, a nicotine patch, or both for smoking cessation. N Engl J Med 1999; 340:685-91.

42. Schnoll RA, Patterson F, Wileyto EP, et al. Effectiveness of extended-duration transdermal nicotine therapy: a randomized trial. Ann Intern Med 2010;152:14451.

43. Petry NM, Martin B, Cooney JL, Kranzler HR. Give them prizes, and they will come: contingency management for treatment of alcohol dependence. J Consult Clin Psychol 2000;68:250-7.

44. Schotter A, Weigelt K. Behavioral consequences of corporate incentives and long-term bonuses - an experimental study. Manage Sci 1992;38:1280-98.

45. Audrain-McGovern J, Rodriguez D, Epstein LH, Cuevas J, Rodgers K, Wileyto EP. Does delay discounting play an etiological role in smoking or is it a consequence of smoking? Drug Alcohol Depend 2009;103:99-106

Copyright $\odot 2015$ Massachusetts Medical Society.

RECEIVE IMMEDIATE NOTIFICATION WHEN AN ARTICLE IS PUBLISHED ONLINE FIRST

To be notified by e-mail when Journal articles are published Online First, sign up at NEJM.org. 